\title{
Incidence of Complications of Thyroid Surgery
}

\author{
Haque GHMS ${ }^{1}$, Farid $\mathrm{N}^{2}$, Islam $\mathrm{SS}^{3}$
}

\section{Abstract}

During the period of July 2009 to June 2012 the study was conducted on 200 cases of thyroid swelling in the Department of ENT and Head-Neck surgery, Rangpur Medical College Hospital, Rangpur. The age range of the study population was from 10 years to 75 years. Female to male ratio was 3.14:1. Diagnosis of all cases was established preoperatively by clinical examination, thyroid function tests, fine needle aspiration cytology (FNAC) and ultrasonogram (USG). Most of the patients were suffering from multinodular goiter. Maximum operations were done in the form of subtotal thyroidectomy followed by hemithyroidectomy. 16.5\% patients were developed complications. Postoperative haemorrhage and recurrent laryngeal nerve paralysis (5\% each) were the most common complications. Among recurrent laryngeal nerve paralysis (4\%) were unilateral and $1 \%$ was bilateral paralysis. In the study $1.5 \%$ deaths were reported due to massive haemorrhage and respiratory obstruction. Considering the above findings, it is mentionable that complications of thyroid surgery can be minimized by sound knowledge of normal and pathologic anatomy and an unhurried, gentle operation technique.

Key words: Thyroidectomy, Postoperative complications.

1. Corresponding Author: Dr. G.H. M. Shahidul Haque Associate Professor, Department of ENT. Manikganj Medical College, Manikgonj. e-mail: ghmshaque@gmail.com

2. Prof. Dr. Nahash Farid Professor and Head, Department of ENT. Northern Medical College, Rangpur.

3. Dr. Sayed Sanaul Islam Medical Officer National Institute of ENT, Tejgoan, Dhaka.

\section{Introduction}

The thyroid gland is located immediately below the larynx on each side of anterior to the trachea which is highly vascular and largest endocrine gland in the body. It secretes hormones which are responsible for both physical and mental growth ${ }^{1}$. The normal gland is impalpable. The term goiter (Latin, gutter = the throat) is used to describe generalized enlargement of thyroid gland ${ }^{2}$. Thyroid swelling is common clinical problem throughout the world $^{3}$. These are also common clinical problem in Bangladesh. In our country the national prevalence is 10$15 \%$, which indicates that the whole country is endemic. The endemically varies from one place to other ${ }^{4}$. Thyroid swelling is prevalent predominantly in females particularly in adult life. The average incidence of endemic in our country including all age and sex groups is $10.5 \%$. The percentage in male and female are $7.21 \%$ and $12.37 \%$ respectively ${ }^{5}$.

Enlargement of the thyroid gland may be due to different conditions. The majority of patients with thyroid enlargement have benign thyroid diseases. Neoplastic, inflammatory and endocrine abnormalities of the thyroid gland are common, affecting approximately $11 \%$ of the general population ${ }^{6}$. As such, surgery of the thyroid gland abnormalities is quite common ${ }^{7}$. Once a decision for thyroid surgery has been made, the extent and type of the operation depends on a number of factors including; patients age, size of the nodule, the suspected preoperative diagnosis including the result of the fine needle aspiration cytology, presence or absence of involved lymph nodes in the neck ${ }^{8}$.

Potential complications of thyroid surgery includes haemorrhage, recurrent laryngeal nerve injury, damage to the parathyroid glands etc. Thyroidectomy is one of the commonest operations for the otolaryngologist and headneck surgeons. Several surgical procedures have been used in the treatment of thyroid disease such as i) Lobectomy or hemithyroidectomy. ii) Subtotal thyroidectomy. iii) Near total thyroidectomy. iv) Total thyroidectomy. v) Total thyroidectomy with neck dissection ${ }^{9}$.The complications which is most feared is trauma to the recurrent laryngeal nerve, estimated to occur between 1 and $10 \%$ of operations ${ }^{10,11}$. Hypocalcaemia is uncommon after subtotal thyroidectomy but is common in the total thyroidectomy. Hypothyroidism developing gradually over a period of months or year after operations 
is a common though acceptable complication of subtotal and total thyroidectomy and is readily treated with thyroxin $^{12}$. As in Bangladesh prevalence of thyroid disease is high and the scope of thyroid surgery is increasing day by day, the study was conducted with the aim to find out the rate of complications of thyroid surgery and to see the different modalities of thyroid surgery performed for thyroid swelling.

\section{Materials and Methods}

The study was conducted at Rangpur Medical College Hospital, Rangpur during the period of July 2009 to June 2012. The diagnosis of thyroid swelling was based on detailed history, thorough clinical examination and relevant investigations such as thyroid function tests (serum $\mathrm{T}_{3}, \mathrm{~T}_{4}, \mathrm{TSH}$ level), Ultrasonogram, Isotope scanning and fine needle aspiration cytology (FNAC). All the data were compiled and tabulated in order o obtained a statistical and comprehensive results of the study.

\section{Results}

Age of the patients ranged from 10 years to 75 years. Most of the patients were $3^{\text {rd }}$ and $4^{\text {th }}$ decades. Out of 200 patients, $76 \%$ were female and $24 \%$ were male. Female to male ratio was 3.14:1. Most of the patients (54\%) were from middle socio-economic status. (Table-I)

Table-I: Age, sex and socio-economic condition of the patients $(n=200)$

\begin{tabular}{cccc}
\hline Parameter & Distribution & Number of patients & Percentage \\
\hline \multirow{2}{*}{ Age } & $10-20$ years. & 34 & $17 \%$ \\
& $21-30$ years. & 56 & $28 \%$ \\
& $31-40$ years. & 49 & $24.5 \%$ \\
Sex & $41-50$ years. & 37 & $18.5 \%$ \\
& $>50$ years. & 24 & $12 \%$ \\
& Female & 152 & $76 \%$ \\
Socio economic & Male & 48 & $24 \%$ \\
status & Pery poor & 30 & $15 \%$ \\
& Middle class & 42 & $21 \%$ \\
& Rich & 20 & $54 \%$ \\
\hline
\end{tabular}

All the patients presented with visible or palpable swelling in front of the neck. Total $34(17 \%)$ patients were presented with other associated symptoms.(Table-II)

Table-II: Presenting symptoms $(n=200)$

\begin{tabular}{ccc}
\hline Symptoms & Number of patients & Percentage \\
\hline Thyriod swelling & 200 & $100 \%$ \\
Cervical lymph & 06 & $03 \%$ \\
adenopathy & 06 & \\
Hoarseness of voice & 10 & $03 \%$ \\
Pain in swelling & 12 & $05 \%$ \\
Weight loss & & $06 \%$ \\
\hline
\end{tabular}

Clinically most of the patients, $48.5 \%$ were multinodular goitre followed by simple nodule $28 \%$.(Table-III)

Table-III: Clinical diagnosis $(\mathrm{n}=200)$

\begin{tabular}{ccc}
\hline Diagnosis & Number of patients & Percentage \\
\hline Simple nodule & 54 & $28 \%$ \\
Toxic nodule & 08 & $04 \%$ \\
Colloid goitre & 21 & $10.5 \%$ \\
Multinodular goitre & 97 & $48.5 \%$ \\
Thyroiditis & 05 & $2.5 \%$ \\
Carcinoma of & 15 & $7.5 \%$ \\
thyroid & & \\
\hline
\end{tabular}

High resolution ultrasonography is anunique tool for diagnosing physical characteristics of thyroid gland. In this study most of the findings showed solid mass in the thyroid gland (44.5\%).Cytological diagnosis is highly accurate, minimally invasive pre-operative diagnostic tool. In our study it was not conclusive in $10 \%$ cases. Other diagnosis was conclusive.(Table-IV)

Table-IV: Ultrasound and FNAC findings $(n=200)$

\begin{tabular}{cccc}
\hline $\begin{array}{c}\text { Type of } \\
\text { investigations }\end{array}$ & Findings & $\begin{array}{c}\text { Number of } \\
\text { patients }\end{array}$ & Percentage \\
\hline \multirow{3}{*}{ Ultrasound } & Solid & 89 & $44.5 \%$ \\
& Cystic & 21 & $10.5 \%$ \\
& Mixed & 90 & $45 \%$ \\
& Negative for malignancy & 145 & $72.5 \%$ \\
& Suspicion of malignancy & 20 & $10 \%$ \\
\multirow{2}{*}{ FNAC } & Positive for malignancy & 15 & $7.5 \%$ \\
& Unsatisfactory & 20 & $10 \%$ \\
\hline
\end{tabular}

In this series subtotal thyroidectomy carried out in $40 \%$ patients and occupied the top of the list followed by hemithyroidectomy $28 \%$.(Table-V)

Table- V: Types of operation performed $(n=200)$

\begin{tabular}{ccc}
\hline Name of operation & $\begin{array}{c}\text { Number of } \\
\text { patients }\end{array}$ & percentage \\
\hline Lobectomy & 24 & $12 \%$ \\
Hemithyroidecomy & 56 & $28 \%$ \\
Subtotal thyroidecomy & 80 & $40 \%$ \\
Near total thyroidecomy & 18 & $09 \%$ \\
Total thyroidecomy & 18 & $09 \%$ \\
Total thyroidecomy with neck & 04 & $02 \%$ \\
dissection & & \\
\hline
\end{tabular}

In this study highest number of complications were hemorrhage and recurrent laryngeal nerve paralysis 5\% each followed by wound infection $3 \%$.(Table-VI) 
Table-VI: Post operative complications $(n=200)$

\begin{tabular}{ccc}
\hline Name of complications & $\begin{array}{c}\text { Number of } \\
\text { patient }\end{array}$ & Percentage \\
\hline Haemorrhage/Haematoma & 10 & $05 \%$ \\
Recurrent laryngeal nerve & Unilateral=8 & $04 \%$ \\
paralysis & Bilateral $=2$ & $01 \%$ \\
Hypoparathyroidism & 04 & $02 \%$ \\
Wound infection & 06 & $03 \%$ \\
Death & 03 & $1.5 \%$ \\
\hline
\end{tabular}

\section{Discussion}

About $7 \%$ of the world population has goitre ${ }^{7}$. In our country, national prevalence of goitre is $17 \%$, which indicates that the whole country is endemic, nodular goitre is more prevalent than defuse goitre. In a report from thyroid clinic, BSMMU, Dhaka, $32.67 \%$ of all thyroid patients has solitary nodules. Carcinoma thyroid usually present as solitary cold nodule or as multinodular goitre. Age ranged in this study from 10 to 75 years. The highest number of cases $(28 \%)$ belongs to the age group of 21 to 30 years followed by $24.5 \%$ in the age group of 31 to 40 years (Table-I). Lalidaet al. in his study of 361 patients found that age ranged from $25-82$ years $^{13}$ and Siddique found maximum incidence in $4^{\text {th }}$ and $5^{\text {th }}$ decades in our country $^{14}$. In this series, 152 patients $(76 \%)$ were female and 48 patients (24\%) were male with female to male ratio 3.14:1 (Table-I). There was a female preponderance in this series but it was lower than the studies of Lalida and Siddique ${ }^{13,14}$. Though there is no close relation between patients with thyroid diseases and socio-economic status, the average socio-economic group having higher incidence $54 \%$ followed by poor group $21 \%$ (Table-I). The cause is not exactly known, itmight be related to illiteracy, superstition and fear of surgery. Regarding presenting symptoms, all the patients presented with thyroid swelling in variable durations. Here 12 patients $(6 \%)$ presented with gradual weight loss and 10 patients $(5 \%)$ presented with pain (Table-II). Multinodular goitre or simplenodulargoitre with large swelling may be associated with difficulty in respiration or difficulty in deglutition which is mostly due to pressure on trachea or oesophagus $^{15}$.

Regarding clinical diagnosis, most of the patients $48.5 \%$ suffered from multinodular goiter followed by simple nodular goitre $28 \%$, colloid goitre $10.5 \%$, carcinoma of thyroid $7.5 \%$, toxic nodule $4 \%$ and thyroiditis $2.5 \%$ (Table-III). This result is close to the observation of Ashraf and Matin (1984) ${ }^{16}$.

Investigations are essential to establish pre-operative physical, functional status and cytopathological nature of the thyroid swelling ${ }^{17}$. All patients had done thyroid hormone profile and most of them showed values within normal limit. Ultrasonography was used to establish physical characteristics and to exclude clinically undetectable nodule of a dominant nodular goitre ${ }^{18}$. Ultrasonography showed $44.5 \%$ solid, $10.5 \%$ cystic and 45\% mixed echo textured goitre, (Table-IV) which was similar to operative findings. Fine needle aspiration cytology (FNAC) is very important, highly specific, most sensitive, minimally invasive preoperative diagnostic tool ${ }^{12,19}$. In our study $90 \%$ were conclusive and $10 \%$ were not conclusive (Table-IV). Most of the operations were done in the form of sub-total thyroidectomy $40 \%$ followed by hemithyroidectomy $28 \%$ and lobectomy $12 \%$ (Table-V). Total thyroidectomy and near total thyroidectomy were done in $9 \%$ cases. Total thyroidectomy with modified radical neck dissection done in $2 \%$ cases of papillary carcinoma with neck node metastasis.

Out of 200 cases, $16.5 \%$ patients developed post-operative complications (Table-VI). This findings nearly consistent with the study R. Moulton et $\mathrm{al}^{20}$. $(14.2 \%)$ but not with the study Asaduzzaman ${ }^{21}(12.5 \%)$. Among the post-operative complications $5 \%$ developed post-operative haemorrhage/ haematoma, due to oozing from remaining thyroid tissue and wound surface which were managed by cauterization and ligation after exploration of the wound. In our series, 10 patients $(5 \%)$ developed recurrent laryngeal nerve paralysis of which 8 were unilateral paralysis and 2 were bilateral (Table-VI). Among 8 patients of unilateral paralysis 6 patients showed gradual improvement of voice in subsequent follow-up and after 3 months, voice were almost normal by compensation of the opposite vocal cord. Other 2 patients do not show significant improvement even after an average period of 3 months follow up. Among 2 patients of bilateral recurrent laryngeal nerve paralysis, one patient was managed by emergency tracheostomy with subsequent follow up and another patient was managed by medical treatment. Transient paralysis may result from pressure on the nerve by edema in which cases recovery can be anticipated. Iqbal et al. found only one recurrent laryngeal nerve damage out of 111 cases of thyroidectomy $(0.9 \%)^{22}$. Another Bangladeshi study by Rahman revealed a 4\% incidence of recurrent laryngeal nerve injury ${ }^{23}$. Lalidaet al. found the incidence of recurrent laryngeal nerve paralysis among 361 patients was $6.09 \%$. The incidence of hypoparathyroidism is as high as 20 percent when total thyroidectomy and neck dissection is performed and as low as $0.9 \%$ for subtotal thyroidectomy ${ }^{24}$. But in this series only 4 patients (2\%) developed transient parathyroid insufficiency (Table-VI) on $3^{\text {rd }}$ postoperative day, which was improved later on. Out of 200 patients, $3 \%$ patients developed wound infection which were managed by exploration and removal of unabsorbed catgut followed by secondary stitch. There were 2 deaths in our series, due to massive hemorrhage on the postoperative period and respiratory obstruction.

In conclusion, a considerable number of various complications were observed during the procedure of thyroid surgery. The mentionable postoperative complications like haemorrhage, recurrent laryngeal nerve damage, hypoparathyroidism and also mortality depends on the extent of surgery. But these crucial postoperative 
complications could be minimized if surgery of thyroid gland performed safely in the majority of patients. A thorough knowledge of various thyroid surgery and potential surgical complications are mandatory for the thyroid surgeon. Successful surgical management of thyroid disease is also based on a sound knowledge of normal and pathologic anatomy and an unhurried, gentle operative technique. Long-term follow up is essential to assess the recurrence and development of hypothyroidism.

\section{References}

1. Guyton AC, Hall JE. Textbook of medical physiology. 11thed. Philadelphia: W.B. Saunders company; 2006.

2. Rains AJH, Charles VM. Bailey and Love's short practice of surgery. 23rded. London: ELBS; 2000.

3. Way LW.Current Surgical Diagnosis and Treatment. 11thed. London: 2003.

4. Mahmood S, Hossain GA, Rahman MU. Awareness of general population regarding goiter.Mym, Med, Journal. 1995;4 (2):86-91.

5. RahamanMd, Taibur. Study of incidence of malignancy in cold solid nodule of thyroid in 40 cases. Dissertation BCPS. 1990: 909-910.

6. Conaris GJ, Manowitz NR, Mayor G.The Colorado thyroid disease prevalence studying. Arch Intern Med. 2000;160:526-534.

7. Harness JK, Organ CHJ, Thompson NW. Operative experience of US general surgery residents in thyroid and parathyroid disease surgery. 1995;118:1017-1063.

8. Clain A. The thyroid gland, Hamilton bailey's Demonstration of physical sign in clinical surgery. 17thed. $1986 ; 155-164$.

9. Watkinson J, C Gaze M, N and Janet A, Wilson. Tumors of the thyroid and parathyroid glands, Stell and Maran's Head and Neck surgery. 4thed. 2000; 459-485.

10. Wade JSH, The morbidity of subtotal thyroidectomy. British journal of surgery. 1960;48:25-42.

11. RiddelV.Thyroidectomy: Prevention of bilateral recurrent nerve paralysis. British journal of surgery. 1970;57:1-11.

12. Hedley AJ, Michie W, Duncan T, Herms G, Crooks J.The effect on remnant size in the outcome of subtotal thyroidectomy for thyrotoxicosis. British journal of surgery. 1972;59: 559-563.
13. Kasemsewan L, Nubthuenetr S. Journal of Otolaryngology. 1997;26(6):32-35.

14. Siddique M. Study of the incidence of complications in thyroid surgery, Analysis of 60 cases operated during Jan 92 to Jan 93 [Dissertation FCPS (surgery)], Dhaka; Bangladesh College of physicians and surgeon. 1994; 4662.

15. Cady B, Sedgwick CE, Meissner WA. Risk factor analysis in differentiated thyroid cancer. Caner. 1979.

16. Ashraf SA, Matin ASMR. Review of thyroid disease in Bangladesh; Analysis of personal series of 91 cases. JBCPS. 1984;2:5-10.

17. Dudley H, Pories WJ (eds). General principles, Breast and Extracranial endocrines in Rob and Smiths operative surgery. 4thed. London: Butterworth scientific; 1986.

18. Cady B, Cotin K, Rossi RL. The effect of thyroid hormone administration upon survival in patients with differentiated thyroid carcinoma. Surgery. 1983;94:978983.

19. Block MA, Dailey GE, and Robb JA. Thyroid nodule indeterminate by needle biopsy. Am J Surg. 1983;20:113203.

20. Moulton-Barrett R,Crumley R, Jalilie S, Segino D, Allison G, Marshak D. Chan Int. Surgery. 1997;82:63-66.

21. Asaduzzaman AKM. Surgical management of thyroid swelling- A prospective study of 40 cases. Dissertation, FCPS (ENT), Dhaka, Bangladesh College of physicians and surgeons. 2006; 69-75.

22. Iqbal M, Rasool MI, Khan M, Malik S, Barkat W. Prospective study of 111 cases of thyroid surgery for postoperative morbidity and mortality. J Pak Med Assoc. 1989;39:201- 204.

23. Rahaman ML. Follow-up study of thyroidectomy. Analysis of 50 cases operated during January 1983 to march 1987 [Dissertation, FCPS (surgery)], Dhaka, Bangladesh College of physicians and surgeons. 1988;88110 .

24. Kaplan EL.Thyroid and parathyroid. In: Schwartz SI, Shires GT, Spinner FC, Hussar WC (eds). Principles of surgery. 6th ed. MC Graw Hill Inc. New York: 1994; 1611-80. 